\title{
Ciência, misticismo e educação: uma análise russelliana da pretensa neutralidade da matemática frente à religião
}

\author{
Júlio César Augusto do Valle*
}

\begin{abstract}
Resumo
O propósito deste artigo consiste na elucidação dos elementos da obra de Bertrand Russell (1872-1970), eminente matemático e filósofo, que tornem possíveis os debates acerca da pretensa neutralidade da matemática diante dos misticismos que sempre estiveram presentes na história da humanidade, mas que, devido aos equívocos que impregnaram sua perspectiva, consideramos, muitas vezes, genericamente obscurantistas e perniciosos. Para isto, tornou-se necessário evidenciar as abordagens à ciência, aos misticismos e à educação na obra russelliana. Pretende-se, portanto, destacando a possibilidade de compreender a matemática como credo, demonstrar que posturas decorrem da tradicional educação matemática que podem favorecer posturas de intolerância religiosa e sugerir, também com Russell, a introdução de uma postura de enfrentamento.

Palavras-chave: Matemática; Bertrand Russell; Misticismo; Filosofia
\end{abstract}

\section{Science, mysticism and education: a russellian analysis of the supposed neutrality of mathematics towards religion}

\begin{abstract}
The purpose of this article is to elucidate the elements of the work of Bertrand Russell (1872-1970), eminent mathematician and philosopher, which make possible the debates about the alleged neutrality of mathematics towards the mysticism that has always been present in human history, but due to misconceptions that pervade their perspective, we consider often generically obscurantist and pernicious. For this, it was necessary to highlight the approaches to science to mysticism and education in Russell's work. It is intended, therefore, highlighting the possibility of understanding mathematics as creed, show that attitudes stem from traditional mathematics education that can foster religious intolerance poses and suggest, also with Russell, the introduction of a confronting posture. Keywords: Mathematics; Bertrand Russell; Mysticism; Philosophy
\end{abstract}

\section{Palavras iniciais sobre matemática, ciência e misticismo}

Tornou-se muito comum associar a matemática, dentre todas as disciplinas do currículo escolar, à neutralidade e à assepsia que caracterizariam com excelência o próprio pensamento, o livre pensar, ou, mais especificamente, o pensamento científico, de que a matemática é evidentemente - a espinha dorsal fundamento de todo o modo de pensar ocidental (RUSSELL, 1957). Todavia, inúmeras correntes de pesquisa e conceituação, mesmo internas à matemática, têm demonstrado os equívocos que sustentam e que decorrem deste modo de entender, particularmente, a gênese do pensamento matemático.

Com efeito, Russell afirma que a metafísica, tentativa de conceber o mundo por meio do pensamento, se originou e se desenvolveu a partir "da união e do conflito de dois impulsos humanos muito diferentes, um induzindo os homens ao misticismo, outro os impelindo à ciência" (RUSSELL, 1957, p. 9). A história demonstra que, conforme a perspectiva russelliana, as mulheres e os homens mais brilhantes da humanidade sentiram a necessidade de conciliar a ciência (mormente representada pelos estudos em matemática) e o misticismo. Russell diria ainda, mais audaciosamente, que para estes, comumente filósofos, "a tentativa de harmonizar os dois foi o que fez a sua vida, e o que, para certos espíritos, sempre tornará a filosofia, apesar da sua árdua incerteza, maior que a ciência ou a religião" (RUSSELL, 1957, p. 9).

Assim, surpreende-nos a postura de um matemático e filósofo reconhecido que defende e enaltece, de algum modo, a complementaridade das ciências e das religiões ou, particularmente, da matemática e do misticismo ${ }^{1}$, bem como porque se convencionou, por muitos motivos, que tais saberes são fundamentalmente antitéticos: a afirmação de um demandaria, portanto, a negação do outro. Cabe-nos, então, o exame dos motivos que orientaram Russell à defesa supracitada.

\footnotetext{
*Endereço eletrônico: julio.valle@usp.br
} 
Antes, contudo, é necessário mencionar - a fim de uma breve apresentação do filósofo em que se fundamentam as ideias deste texto - a relevância da contribuição teórica de Bertrand Russell para a filosofia e para a matemática. Descendente de uma família tradicional e importante na história britânica, Russell tornou-se matemático e contribuiu significativamente com a Lógica ao buscar fundamentar toda a matemática a partir deste domínio. A tentativa de tornar a Lógica o fundamento último para a matemática - e, mais pretensiosamente, para o próprio pensamento conduziu-o, junto a Gottlob Frege (1848-1925), a conceber as vias para o Logicismo, uma importante corrente de conceituação do conhecimento matemático.

Posteriormente, Russell concluiria seus estudos em filosofia contribuindo significativamente para a elucidação de muitos temas ainda obscuros para a investigação filosófica como, por exemplo, a moralidade e o poder, a guerra e a paz. Militante pacifista, Russell esteve ao lado de muitos homens e mulheres importantes de sua época lutando pelo desarmamento nuclear, tornou-se particularmente reconhecido neste certame ao escrever e publicar o Manifesto Pugwash ou Manifesto Russell-Einstein, que recebe este nome devido à assinatura do físico, dias antes de seu falecimento (VALLE, 2015).

Todas estas contribuições, especialmente aquelas que se relacionam à matemática e à filosofia, tornam-se bastante relevantes para os estudos posteriores. É necessário também ressaltar que, embora Russell tenha manifestado mudanças de posição frente aos temas sobre os quais escreveu, toda a sua obra permanece relevante por indicar o trajeto de seu desenvolvimento filosófico, além de seu amadurecimento intelectual. Tomaremos, portanto, alguns tópicos de sua trajetória filosófica, apresentados numa coletânea de textos denominada "Misticismo e Lógica" (RUSSELL, 1957), complementados por referências de outros escritos.

Primeiro, há de se concordar com Russell em sua observação de que um credo, de fundamento religioso, difere necessariamente do conhecimento científico porque enquanto o primeiro se pretende verdadeiro, eterno e imutável, a ciência deve ser eternamente uma tentativa, "aguardando que modificações em suas teorias sejam necessárias, ciente de que seu método é logicamente incapaz de chegar à completa e final demonstração" (RUSSELL, 1997, p. 14).

Pode-se notar que, conforme a definição russelliana, ciência e religião não são necessariamente antitéticas, a priori. Porém, se somos condicionados a compreendê-las assim, o que as torna aparentemente divergentes? Ademais, considerando os processos educativos como potenciais transmissores e legitimadores das formas tradicionais de pensar, sentir e agir de toda cultura, de que modo e com que profundidade a educação se relaciona com o cenário descrito? E, se tomarmos, como faz Russell, a matemática como representante por excelência do método científico, que atitudes evidenciam ou obscurecem este debate no decorrer do ensino desta disciplina? Tais dúvidas constituem o escopo que orienta a abordagem construída neste texto.

\section{Do lugar de que emergem a ciência e a religião, uma impregnação mútua}

Há de se verificar, em segunda instância, a afirmação de Russell de que as posturas mística e científica, como o filósofo as denominava, decorrem ambas de um mesmo desafio, a saber, a intelecção do mundo, a leitura e posterior compreensão dos fenômenos naturais e sociais que interagem construindo nossa realidade. Ambas diferem, contudo, no método de que se valem no anseio de solucionar o desafio a que se propõem: "quando um homem da ciência nos conta o resultado de uma experiência, ele também nos conta como o experimento foi realizado; outros podem repeti-lo, e se o resultado não é confirmado, não pode ser aceito como verdade", ao passo em que "o místico pode ter certeza que ele conhece, mas não tem necessidade de testes científicos" (RUSSELL, 1997, p. 178).

Ainda metodologicamente, o matemático observa que:

O homem da ciência, quando deseja que os outros vejam o que ele viu, prepara o microscópio ou o telescópio; ou seja, ele faz alterações no mundo externo, mas demanda do observador apenas a visão normal. $O$ místico, por outro lado, demanda alterações no observador por jejum, por exercícios de respiração e por uma abstenção cuidadosa da observação externa (RUSSELL, 1997, p. 187).

É importante, aqui, ressaltar que, à medida que diferem metodologicamente na tentativa de solucionar angústias muito similares em essência, 
não podem existir motivos para enaltecer ciência em detrimento de religião, ou o inverso. $\mathrm{O}$ entendimento de que o conhecimento produto do método científico é verdadeiro em absoluto constitui, inclusive, uma das maiores distopias da racionalidade moderna. Afinal, se o método científico determina somente, internamente, o que se configura como conhecimento científico, seria um equívoco, ingênuo ou malicioso, tomá-lo como régua, unidade padrão, para medir outros saberes que não decorrem do mesmo método.

Qualquer análise desta natureza terminaria evidentemente por concluir que as religiões, os credos e todas as formas de saber popular não passam de meras falácias. Daí, depreenderíamos fatalmente, como nos demonstra a história da humanidade, a distância que divide as ciências das religiões. Apresenta-se, portanto, este equívoco como principal responsável pela divisão entre ciência e religião, com prejuízo de valor acentuado para a última. Não se pretende, obviamente, dirimir o prejuízo que algumas religiões causaram à história da ciência, e particularmente da matemática também, mas oferecer outra perspectiva para a análise desta mesma história.

Pretende-se, não há como negar, construir uma perspectiva mais e mais isenta da negação da ciência pela religião ou da religião pela ciência, ambas absolutamente distorcidas pelas incongruências que deslegitimam um exame detido. Afinal, como veremos adiante existe, de fato, uma impregnação mútua em uma ampla variedade de elementos que concernem tanto à ciência e à matemática como às religiões, ao místico. Russell ilustra este entendimento observando que em toda religião profundamente séria existe um caráter de submissão que decorre da inescapável assunção dos muitos limites do poder humano. Assim, ao examinar criticamente as religiões predominantes no início do século XX, o matemático concluiria, ademais, que "a submissão que a religião inculca na ação é essencialmente a mesma, em espírito, que a ciência ensina ao raciocínio; e a neutralidade ética através da qual tem logrado vitórias é o resultado dessa submissão" (RUSSELL, 1957, p. 40).

Com efeito, vale observar o sentido de submissão a que se refere Russell precisamente porque o matemático também constatava que este mesmo sentido desaparecia no mundo moderno "com os seus rápidos sucessos materiais e sua crença insolente nas infindas possibilidades do progresso" (RUSSELL, 1957, p. 40). De fato, o matemático apresentou modos revolucionários de pensar em meio ao recrudescimento do sentir que marca sua época - o que se desvela em alguma medida em sua crítica à pretensa neutralidade que devia ter a ciência:

A ciência devia ser neutra, já que o argumento é científico, para ser conduzido exatamente como um argumento deve ser conduzido sobre um experimento incerto. A ciência depende da percepção $e$ da inferência; sua credibilidade se deve ao fato de que as percepções são tais que qualquer observador pode testar (...) A ciência não devia ter expectativa, positiva ou negativa, sobre o resultado (RUSSELL, 1997, p. 178).

Evidentemente, não existem somente correspondências entre os modos como surgem as religiões e as ciências e Russell, ao destacar suas divergências, declara que o misticismo, conquanto se possa exercer sobre ele determinada moderação, pode contribuir à perspectiva científica. Mais especificamente, talvez "exista um elemento de sabedoria que se pode aprender da maneira mística de sentir, e que não parece ser atingível de nenhuma outra maneira" (RUSSELL, 1957, p. 20), conforme afirmaria o matemático. Ao mesmo tempo, Russell critica arduamente as teorias vigentes sobre o evolucionismo como filosofia científica e sublinha que "uma filosofia legitimamente científica será mais humilde, mais minuciosa, mais árdua, oferecerá menos brilho de miragens externas para lisonjear esperanças falazes", e mais: "será mais indiferente aos fatos, e mais capaz de aceitar o mundo sem a imposição tirânica de nossas exigências humanas e passageiras" (RUSSELL, 1957, p. 41).

Nesse sentido, Russell declara que há um elemento na religião, o mais desejável, completamente dissociado das descobertas da ciência: para o matemático, "no melhor dos santos e místicos, existiu em combinação a crença em determinados dogmas e certo modo de sentir sobre os propósitos da vida humana" (RUSSELL, 1997, p. 17). Este modo de sentir deve ser ressaltado em detrimento dos modos convencionais de sentimento, sobretudo porque "o homem que sente profundamente os problemas do destino humano, o desejo de diminuir os sofrimentos da humanidade tem a esperança de que o futuro realizará as melhores possibilidades de nossa espécie" (RUSSELL, 1997, p. 17). Trata-se, não há dúvida, de uma divergência notável entre a ciência e as religiões. Afinal, "quanto mais a religião consiste em um modo de sentir, mais 
do que um conjunto de crenças, a ciência não pode tocá-la" (RUSSELL, 1997, p. 17). Daí sua complementaridade.

Ademais, existe um elemento que se deve sobrelevar neste exame russelliano, que é precisamente onde se fundamenta a complementaridade entre o misticismo e a perspectiva científica enunciada por Russell: trata-se, com efeito, do lugar de que emergem a ciência e a religião. Se recorrermos à historiografia da ciência e das religiões, verificamos sem muita dificuldade que ambas emergem a partir das mesmas perguntas, dos mesmos medos e angústias. Compreender os fenômenos naturais, descobrir a origem dos planetas, do universo, e da vida nestes planetas, examinar quais têm sido as finalidades da existência... Inúmeras dúvidas orientaram o surgimento e o desenvolvimento das ciências, das religiões e de toda forma de saber.

Até mesmo a cautelosa e paciente investigação da verdade pela ciência, que parece a vera antítese da súbita certeza do místico, pode ser incentivada e nutrida pelo próprio espírito de reverência em que o misticismo vive e se move. (...) A razão é mais uma força harmonizadora, controladora, do que criadora. Mesmo no domínio do mais puramente lógico, é a visão que em primeiro lugar atinge o novo (RUSSELL, 1957, p. 20-21, grifos nossos).

Precisamente por esse motivo, Russell diria que ambas, ciência e religião, aparentemente antitéticas são alimentadas por uma necessidade de responder às mesmas questões, mas, mais que isso, o matemático também afirma que, em alguma medida, toda forma de misticismo é responsável pela formulação de outras, novas, perguntas de que a ciência imediatamente se apropria. Existe, portanto, uma retroalimentação permanente entre ciência e religião, entre o lógico e o místico - uma impregnação mútua - que parte do lugar de onde emergem, mas que não se limita somente a este lugar.

\section{Matemática e fé oscilando entre o lógico e o místico}

De fato, ao examinarmos a história da matemática encontraremos uma miríade de referências aos modos como esteve sempre impregnada de muito misticismo, conduzindo-a diversas vezes ao obscurantismo estético e semântico da Idade Média ou à cegueira diante do Iluminismo, que havia conferido uma roupagem respeitável aos misticismos que superaram o obscurantismo anterior. Trata-se, certamente, de uma constatação bastante significativa. Afinal, como dito anteriormente, compreendemos consonantes com Russell a matemática como o fundamento da ciência moderna, sua espinha dorsal.

Propomos, precisamente por esse motivo, um exame das características analisadas por Russell que evidenciam esse vínculo do pensamento matemático com o misticismo. Este vínculo desconstrói evidentemente a pretensa neutralidade da matemática diante dos mais variados modos de pensar e sentir que, em diferentes épocas, foram classificados como misticismos obscurantistas, em oposição nítida à clareza e ao rigor enunciativo da matemática. Há de se reconhecer, desde o início, neste exame o caráter fundamentalmente contemplativo que desenvolve a matemática nas sociedades denominadas clássicas. Havia, portanto, uma dinâmica de contemplação ao estudo da matemática muito semelhante à contemplação dos grandes astros, da natureza e da própria existência.

Sobre isso, Russell afirma que, como muitas religiões na história da humanidade, "a matemática não era empregada pelos gregos como é pelos modernos, para facilitar processos industriais; era uma atividade 'fidalga', valorizada pela sua própria finalidade de conceder a verdade eterna" (RUSSELL, 1956, p. 164). Esse caráter de contemplação, sobretudo, originário dos inúmeros padrões percebidos pelos matemáticos no mundo sensível, permitiu, inclusive, o surgimento de um entendimento, "segundo o qual o mundo visível era condenado como uma coisa de segunda classe" (RUSSELL, 1956, p. 164). Trata-se, efetivamente, de um caráter muito diverso do que conhecemos na atualidade. Na verdade, como complementa Russell, foi Arquimedes quem prefigurou o uso moderno da matemática inventando máquinas de guerra para defesa de Siracusa contra os romanos, mas "um soldado romano o matou, e os matemáticos retiraram-se de novo para a sua torre de marfim" (RUSSELL, 1956, p. 164).

Esclareceu-se, de fato, no início do texto que a análise russelliana parte da constatação de que toda tentativa de compreender o mundo emerge e se desenvolve por meio da união ou do conflito entre duas atitudes - a científica e a mística. Assim, Russell avalia que, "dentre os primitivos filósofos 
gregos, os jônios eram mais científicos e os sicilianos mais místicos" e que Pitágoras consistia em um exemplo de curiosa mistura destas duas tendências: "a atitude científica levou-o à sua proposição de triângulos retângulos, enquanto a sua introspecção mística o exortou a não comer feijão" (RUSSELL, 1966, p. 14). Seus discípulos, como se esperaria conforme a perspectiva enunciada, "dividiram-se em adeptos dos triângulos retângulos e detestadores de feijões" (RUSSELL, 1966, p. 14).

Então, com o tempo, os herdeiros do pensamento matemático e da estrutura demonstrativa receberam um legado em que se podia notar "na especulação matemática helênica, certo matiz de misticismo, notado particularmente, no pensamento de Platão quanto à matemática". Platão, aliás,

incorpora ambas as atitudes, a científica e a mística, sob uma forma superior à adotada por seus predecessores, mas o misticismo dele é distintamente predominante e sempre sai vitorioso, quando o conflito assume certa violência. Platão, além disso, adotou dos eleáticos o sistema de utilizar a lógica para derrotar o senso comum, e assim deixar o campo livre ao misticismo - um sistema ainda hoje empregado pelos adeptos da tradição clássica (RUSSELL, 1966, p. 1415).

Este excerto revela, portanto, a centralidade da função desempenhada pela matemática orientada à crítica e à desconstrução do senso comum, místico e não-científico por natureza. Podemos notar, particularmente, a construção de um paradigma científico em que a matemática - com sua pretensa neutralidade, assepsia, e promissora busca pela verdade absoluta - legitima determinadas compreensões do mundo e marginaliza outras, quase que tão arbitrariamente como a forma em que fora concebida. A matemática, portanto, construída e validada no centro de uma cosmovisão bastante específica, tem sido utilizada desde então como ferramenta para validar ou não outras leituras da realidade, valendo-se obviamente de sua pretensiosa neutralidade.

Esse uso da matemática - que, inclusive, tem sido desempenhado pela própria ciência -, prefigurado por Platão, omite, contudo, que a matemática se apresenta, desde seu surgimento, embebida dos mesmos misticismos a que aparentemente se contrapõe. Misticismos estes impregnando a matemática internamente em suas estruturas e também externamente nas compreensões que se tem acerca do pensamento matemático. $\mathrm{O}$ senso estético dos gregos, por exemplo, dominou suas especulações a respeito do movimento dos corpos celestes e os impediu de cogitar a possibilidade de que os astros se movessem conforme elipses, ao invés de círculos ou complexos de círculos, embora conhecessem, à época, muito sobre as elipses e suas propriedades matemáticas. Seu senso estético, embebido de misticismos, "fez com que eles rejeitassem tudo, menos a hipótese mais simétrica" (RUSSELL, 1997, p. 29)22.

Ainda assim, não é somente no âmbito interno que a matemática e a ciência se apresentaram impregnadas do misticismo e da cultura nãocientífica das sociedades em que afloraram, mas também no âmbito externo. Isto corresponde a afirmar que muito do misticismo que serve à matemática e à ciência também está presente na maneira como ambas interferem na realidade, prejudicando-a inclusive. Russell evidencia a validade desta asserção ao construir o seguinte relato:

Pitágoras, como todos aprendemos na
juventude, descobriu a proposição de que a
soma dos quadrados nos lados de um
triângulo retângulo é igual ao quadrado da
hipotenusa. Dizem que sacrificou um boi
quando descobriu esse teorema. Se isso foi
verdade, o tal boi figura como primeiro
mártir da ciência (RUSSELL, 1966, p. 123).

Ao afirmar que o referido boi representa somente o primeiro mártir da ciência, o matemático ressalta sua perspectiva crítica ao pensamento científico e aos prejuízos causados à humanidade. Com efeito, Russell defendia que a ciência ainda é muito recente, quando comparada às religiões e, por isso, sua interferência no mundo ainda é menor do que a religiosa. Em seus termos, "a ciência ainda não conquistou a autoridade da tradição e da longa influência que a religião tem sobre a maioria", embora o matemático também soubesse que "a ciência é perfeitamente capaz de adquirir a mesma autoridade e de submeter-se ao mesmo grau de aquiescência que caracterizou a atitude do homem em face dos preceitos religiosos" (RUSSELL, 1977, p. 177). Russell não desconhecia, portanto, os prejuízos causados pela religião à humanidade, mas ponderava: 
A religião existe desde antes da aurora da história, enquanto que a ciência existe, no máximo, há quatro séculos. Mas quando a ciência for velha e venerável, controlará nossa vida tanto quanto a religião. Prevejo a época em que todos aqueles que se batem pela liberdade do espírito humano terão de se rebelar contra a tirania científica. Entretanto, a haver tirania, é preferivel que seja científica (RUSSELL, 1977, p. 177, grifos nossos).

A compreensão de que a perspectiva científica - e, portanto, a matemática em que se fundamenta - ainda demonstra um misticismo muito mais obscurantista do que aqueles que a mesma perspectiva se dedica a criticar propicia, primeiro, um entendimento mais completo da ciência; mas, mais que isso, chama a atenção à problemática fundamental de que decorrem muitos equívocos: a ciência não está isenta do que ela própria considera misticismos.

Quando recordamos que a perspectiva científica considera toda forma de saber ou suposição (superstição) sem embasamento científico decorrente de leis causais da lógica matemática e da inferência - como misticismo ilógico, somos orientados à crítica de inúmeros elementos que ainda impregnam a perspectiva científica e que, conforme sua própria definição, deveriam ser postos em suspeição: a relação entre sujeito e objeto na pesquisa; a objetividade da pesquisa, a neutralidade do pesquisador em relação ao objeto/produto da pesquisa e a expectativa de resolver todos os dilemas que assolam a humanidade na atualidade por meio da ciência constituem elementos deste conjunto.

A matemática, evidentemente, não se exime da mesma problemática e isto significa que não existem somente exemplos da história antiga da matemática que a vinculam ao misticismo e à cultura da sociedade da época, mas nossos próprios modos de entender, conceituar, interpretar a matemática na atualidade também correspondem à fé mística que moveu muitas culturas no horizonte das religiões ${ }^{3}$. A matemática, portanto, oscilou - e ainda oscila - entre o lógico e o místico. A seguir, verificamos alguns momentos da obra russelliana em que o autor sintetiza seu modo de compreender a matemática neste viés:

A matemática, encarada como deve ser, possui não apenas verdade como suprema beleza - fria e austera beleza, como o da escultura, que não fala a parte nenhuma de nossa natureza mais fraca, despida dos esplendorosos adereços da pintura ou da música, $e$, no entanto, sublimemente pura, $e$ capaz de rigorosa perfeição, que só se iguala na grande arte. (...) $O$ que é melhor na matemática merece não apenas ser aprendido como tarefa, mas assimilado como parte do pensamento cotidiano, $e$ frequentemente reapresentado à mente com incentivo sempre novo. (...) Distante das paixões humanas, distante mesmo dos lamentáveis fatos da natureza, as gerações aos poucos criaram um cosmos ordenado, onde o pensamento puro pode residir como na sua vivenda natural, e onde pelo menos um dos nossos impulsos mais nobres pode fugir do triste exílio do mundo real (RUSSELL, 1957, p. 73-74).

A excelência característica da matemática só se encontra onde o raciocínio é rigidamente lógico: as regras da lógica são para a matemática o que as da estrutura são para a arquitetura (RUSSELL, 1957, p. 74).

A matemática nos leva ainda mais longe do que é humano, à região da necessidade absoluta, a que se devem conformar não apenas o mundo real como todos os mundos possíveis; e mesmo aí constrói sua moradia ou, por outra, encontra uma habitação eternamente de pé, onde os nossos ideais são inteiramente satisfeitos e não se frustram nossas melhores esperanças (RUSSELL, 1957, p. 81-82).

Não apenas é a matemática independente de nós e de nossos pensamentos, como, noutro sentido, nós e todo o universo das coisas existentes somos independentes $d a$ matemática. A apreensão dessa característica puramente ideal é indispensável para que compreendamos direito o lugar da matemática entre as artes (RUSSELL, 1957, p. 82).

Dentro da sua própria esfera, a matemática é uma resposta completa àquele tipo de ceticismo que abandona a busca de ideais por ser árdua a estrada e incerta a meta a 
atingir. (...) A matemática é uma negação perpétua desse ceticismo; pois o seu edifício de verdades continua inabalável $e$ inexpugnável a todas as armas da dúvida cínica (RUSSELL, 1957, p. 84-85).

A matemática pura consiste inteiramente de uma série de asserções de que, se tal ou qual proposição é verdadeira em relação a qualquer coisa, então tal ou qual proposição é verdadeira em relação a uma coisa dada. É essencial não discutir se a primeira proposição é realmente verdadeira, e não mencionar o que é qualquer coisa, que se supõe ser verdade. (...) Assim a matemática pode ser definida como matéria na qual jamais sabemos do que estamos falando, nem se o que dizemos é verdade (RUSSELL, 1957, p. 88).

Não somente os trechos das obras russellianas são elucidações importantes de seu modo de compreender a matemática como também revelam, mais genericamente, nossa maneira de conceber a disciplina na modernidade. Na atualidade, herdamos certamente muito desta fé mística na potencialidade criativa e no rigor enunciativo da matemática e isso se desvela em nossa postura notoriamente contemplativa - e mesmo de certa temeridade - diante da matemática. Não haveria problema, entretanto, se a matemática não estivesse no centro de uma racionalidade - dita científica - que reiteradamente agride outros modos de pensar também impregnados da mesma postura contemplativa e temerária. A matemática não está, como vimos, isenta do mesmo misticismo de que dependem as religiões de modo que não há neutralidade alguma da matemática em relação às religiões. Ainda que aparentem estar separadas por enormes distâncias, o comportamento humano, social, diante de ambas não diverge, sobretudo nos elementos destacados.

Em síntese, apesar de a matemática permanecer, durante séculos, impregnada de um misticismo que, em sua origem, lhe deu forma e propósito; há tempos, podemos vê-la desconectada de seu passado místico. Mais grave, a matemática nascida há milênios no seio de sociedades muito místicas e, definitivamente, legitimada em meio ao senso estético impregnado de misticismos na Antiguidade Clássica - tornou-se pedra angular no combate a todo modo de pensar e sentir que se distanciasse da racionalidade científica, que a adotou como primogênita.

Preocupa-nos, então, a assimetria e os danos que caracterizam permanentemente este combate. Assimetria, pois a matemática está associada fundamentalmente à razão e, portanto, positivamente, à "verdade" - ideia concebida, talvez, a partir da possibilidade, ainda que somente internamente, de verificar a veracidade de suas demonstrações ${ }^{4}$ E danos porque incontáveis injustiças têm sido perpetradas a determinadas religiões já marginalizadas e prejudicadas pelos processos de aculturação, colonialismo - e neocolonialismo - e, sobretudo, de imperialismo, conduzindo sociedades etnocêntricas à xenofobia e à intolerância religiosa, sobretudo. Comprovamos tais danos ao constatar que, nos últimos anos, as agressões - violências físicas ou simbólicas - aos religiosos e, sobretudo, às religiões de matriz africana e afro-brasileira aumentaram exponencialmente ao passo em que as sociedades imaginam estar caminhando rumo à clareza, como fizeram as sociedades que chegaram ao Iluminismo, ao exaltar a beleza estética e o rigor da matemática, representante por excelência das matérias exatas e da perspectiva científica.

Deparamo-nos, portanto, com um inescapável dilema apresentado, com contornos mais nítidos, pela pós-modernidade: se, por um lado, não podemos redimir as religiões, sobretudo aquelas que se institucionalizaram, de toda mácula e prejuízo que causaram à humanidade; por outro lado, também não podemos, sob uma perspectiva ingênua que tende ao positivismo, exaltar a ciência ou o método científico em oposição aos credos religiosos. Com efeito,

A questão está agora, contudo, entrando em uma fase completamente nova por dois motivos: primeiro, a técnica científica está se tornando mais importante em seus efeitos do que o temperamento científico da mente; segundo, as religiões mais recentes estão tomando o lugar do cristianismo e repetindo os erros dos quais a cristandade se arrepende (RUSSELL, 1997, p. 244-245).

Parece-nos, então, que a postura de Russell, crítica, conciliatória e não dogmática, representa, de fato, a atitude mais apropriada diante deste dilema.

Cabe-nos ressaltar, contudo, que as escolas se apresentam muito distantes deste entendimento e desta postura conciliatória, o que pode de algum 
modo reiterar os preconceitos em que se fundamenta a intolerância religiosa. Não se trata de uma coincidência, é óbvio, observar que a matemática dispõe da centralidade absoluta nos mais diversos currículos, sobretudo nos currículos técnicos ou científicos que prevalecem na maioria dos países. O conjunto de conceitos e de ideias que a educação matemática tradicional está predisposta a transmitir, ainda que subjetivamente, somente corrobora posturas de muito ceticismo e criticidade aos misticismos mais gerais - o que pode não caracterizar um problema em si. O problema, ao invés disso, se situa na percepção de que estas posturas têm conduzido à intolerância religiosa, distorcidas pelos dogmas de religiões obscurantistas. Russell demonstrou plena consciência dos riscos desta e de outras posturas análogas ao afirmar que "um dos maiores perigos de nosso tempo é o fanatismo nacionalista e teológico" (RUSSELL, 1951, p. 145).

Conforme este exame, orientado pela proposição de que os processos educativos operam transmitindo e legitimando as formas tradicionais de pensar, sentir e agir de toda cultura, nossas dúvidas se deslocam e passam às seguintes: existe alguma possibilidade de a educação matemática não operar legitimando tais preconceitos? A matemática e, em consequência, a educação matemática podem servir ao combate, não das religiões e do misticismo, mas da intolerância religiosa e das violências que dela decorrem?

\section{A compreensão russelliana da educação e de seus propósitos}

Antes de prosseguir com este exame, cabe observar como Russell compreendia a educação e, em particular, a educação matemática. Para isso, observamos que o matemático compreende que "a educação não pode ser confinada à instrução, à comunicação de informação definida sobre vários assuntos, porque essa informação, em si e por si mesma, é útil na vida diária" (RUSSELL, 1957, p. 46). Contudo, apesar de notar que a educação básica seja quase inteiramente desse gênero, Russell destaca que "a instrução, por necessária que seja, não constitui educação per se no sentido em que desejo considerar a palavra" (RUSSELL, 1957, p. 47). Para o matemático, a educação, ao invés disso, "pode ser definida como a formação, por meio da instrução, de certos hábitos mentais e de certa atitude em relação à vida e ao mundo" (RUSSELL, 1957, p. 47).

Isso porque, conforme enuncia a filosofia russelliana, cada impulso ou pulsão humana "tem o seu processo constitucional de pensamento, conhecimento e reflexão, através do qual são previstos os possíveis conflitos, sendo os impulsos passageiros controlados pelo impulso unificador que se pode chamar sabedoria" (RUSSELL, 1957, p. 48). A expectativa do matemático, portanto, com a educação é destruir a crueza do instinto e aumentar, por meio do conhecimento, a variedade e a profundidade dos contatos do indivíduo com o mundo exterior, "tornando-o não mais uma unidade a lutar isolada, mas um cidadão do universo, abrangendo no âmbito dos seus interesses países distantes, regiões remotas do espaço, e vastos trechos do passado e do futuro" (RUSSELL, 1957, p. 48).

Em síntese, para Russell, "o principal objetivo moral da educação é este simultâneo arrefecimento da insistência do desejo e a ampliação do seu escopo" (RUSSELL, 1957, p. 49). Mais especificamente,

A educação, considerada como processo de formação de nossos hábitos mentais e nossa atitude perante o mundo, deve ter seu sucesso medido na proporção em que o resultado se aproxima desse ideal; quer dizer, na proporção em que nos dá uma visão genuína de nossa posição na sociedade, da relação de toda a sociedade humana com o seu ambiente não-humano, e da natureza do mundo não-humano em si, independentemente de nossos desejos e interesses (RUSSELL, 1957, p. 49-50).

Era evidente para o matemático, à época, que a matemática em pouco ou nada havia contribuído para este que devia ser, conforme sua própria filosofia, o propósito orientador da educação. Em seus termos, "tão pouco têm os matemáticos feito da beleza a sua meta que quase nada na sua obra possui esse propósito consciente" (RUSSELL, 1957, p. 74). Com efeito, a distância entre o propósito da educação matemática e a realidade deste ensino aborreciam tanto Russell que, em diversos momentos em suas obras, encontramos recomendações, sobretudo metodológicas, sobre como orientar o ensino da disciplina. Segue um exemplo neste sentido:

Atualmente, no que tange à aritmética, o menino ou menina recebe um conjunto de regras, que se apresentam como nem verdadeiras nem falsas, mas apenas como a 
vontade do professor, modo pelo qual, por alguma razão insondável, o mestre prefere praticar o jogo. Sem dúvida, isto é inevitável, até certo ponto, num estudo de tanta utilidade prática definida; mas assim que seja possível, as razões das regras devem ser enunciadas pelos meios que mais bem falem à mente infantil. Em geometria, em vez do aparelhamento tedioso de provas falazes de truísmos óbvios, que constituem os começos de Euclides, deveria ser permitido ao aluno imaginar inicialmente a verdade de tudo quanto fosse evidente, e deveria aprender demonstrações de teoremas que são ao mesmo tempo assombrosos e facilmente verificáveis por meio do desenho, como o que demonstra que três ou mais linhas encontram-se num ponto (RUSSELL, 1957, p. 75).

A matemática e a educação matemática fracassavam notoriamente em seu propósito também porque, conforme a filosofia russelliana, "toda tentativa de persuadir as pessoas de que algo é bom (ou ruim) em si, e não meramente por seus efeitos, depende da arte de emergir sentimentos e não de um apelo à evidência" (RUSSELL, 1997, p. 235). Podese afirmar, por conseguinte, que a educação matemática não atinge seu propósito, pois que sua assepsia, essa neutralidade aparente, a mantem dissociada do cotidiano e dos problemas diários dos educandos. A matemática e seu ensino não comunicam, portanto, nem dialogam com o sentimento dos educandos.

Pode-se afirmar, inclusive, que a matemática e seu ensino conservaram-se tradicionais mesmo em meio às mais transformadoras crises que atingiram as sociedades nos últimos séculos. Ambas não comunicam porque tentam dialogar com jovens e adultos de outras épocas e não com estes nossos que, na atualidade, convivem com uma marcante efervescência de saberes e informações. Nos termos de Russell, "as crianças deviam ser trazidas a tornarem-se cidadãos do mundo no qual têm de viver, não no mundo daqueles séculos intolerantes em meio aos quais a cultura acadêmica adora habitar" (RUSSELL, 1951, p. 147).

Para Russell, havia o entendimento assertivo de que se, por um lado, nossos jovens "deveriam ter uma nova moralidade de crescimento e mútua adaptação, com possibilidades consequentes de liberdade, em lugar da velha moralidade de proibições, conflitos, vitórias e derrotas" (RUSSELL, 1951, p. 147); por outro, a matemática e seu ensino tradicionais não corroboravam em nada tais perspectivas.

Preocupantemente, portanto, o ensino de matemática - fundamentado, sobretudo, no cientificismo e no tecnicismo predominantes nos currículos escolares -, na atualidade, permite o desenvolvimento de um "temperamento" frente à ciência muito distinto daquele que orientou a humanidade às maiores descobertas. Russell o caracteriza, inclusive como "um temperamento cheio do senso de poder ilimitado, da certeza arrogante e do prazer de manipulação até mesmo de material humano" - e completa, dizendo se tratar do "oposto do temperamento científico" (RUSSELL, 1997, p. 245). Não se pode negar, contudo, que a matemática e seu ensino contribuam significativamente para promovê-lo. Retomamos, então, nossa dúvida: pode a matemática, embebida deste temperamento tão avesso, se opor à intolerância religiosa?

\section{Por um ensino de matemática contra o ódio!}

Deve-se argumentar, de início, que, sob a égide do pensamento russelliano, "nenhum professor deve ser tolerado se ensina hostilidade a algum grupo, sejam judeus, negros ou plutocratas" (RUSSELL, 1951, p. 148). Isto porque o matemático sempre esteve convicto na possibilidade de transformar a realidade, ainda que de maneira mais lenta, sem violência alguma. Mais especificamente,

$O$ ensino do ódio, por mais socialmente perniciosa que possa ser a classe contra a qual o ódio é direcionado, sempre injeta veneno no sistema social. Quando o propósito imediato do ódio é atingido, a emoção sobrevive como um hábito e procura por novas vítimas. Toda defesa de uma mudança social deve ser positiva e não negativa. Deve enfatizar as coisas boas em um possivel futuro mais do que as coisas ruins no presente (RUSSELL, 1951, p. 148).

Para atingir e fortalecer a vontade de transformar a realidade por meio do ensino de matemática, é preciso, como vimos, que todo educador tenha consciência de que a matemática não é neutra e, mais, de que sua pretensa neutralidade omite muito do prejuízo que a disciplina e a racionalidade científica que fundamenta acometem 
às demais formas de saber. Analogamente, por isso, Russell afirma que "devemos estudar matemática se quisermos melhorar uma espécie de trigo ou produzir um couraçado" (RUSSELL, 1958, p. 36-37). A matemática permite o desenvolvimento de ambas as posturas.

Com efeito, pode-se assassinar um indivíduo - continua o matemático - com um bisturi de cirurgião que fora construído com o propósito de salvar vidas. Em seus termos, "a matemática, que parecia um bisturi de cirurgião, assemelha-se mais, na realidade, a uma acha de guerra" (RUSSELL, 1958, p. 36-37). A matemática, portanto, construída com um propósito muito mais nobre (como o bisturi da metáfora russelliana), tem sido utilizada na história para fins avessos aos tais propósitos (como a acha de guerra) $)^{5}$.

Em síntese, matemáticos e educadores matemáticos podem (e devem) enfrentar o ódio mistificado, muitas vezes, por obscurantismos positivistas - alicerce da intolerância religiosa, contanto que se conscientizem da pretensa neutralidade da matemática diante dos misticismos, dos credos e das religiões. Isto porque, de algum modo, existe determinada intencionalidade sustentando as aparências neutras e assépticas que caracterizam o ensino da disciplina e esta mesma intencionalidade deve também ser combatida.

Sob essa perspectiva, o matemático, retomando seus propósitos da educação, escreve que:

Faria as crianças conscientes, do mesmo modo, das maneiras e costumes das tribos e nações completamente remotas para elas. Faria com que elas, quando ocorresse de conhecerem um zulu, não sentissem que ele é estranho e remoto, mas pensassem " $A$ h, sim, eu conheço seu comportamento porque vi um filme sobre ele". A educação, conduzida nestas linhas, faria mais do que muitos livros para curar o provincialismo no espaço e tempo e fazer com que as crianças percebessem que o verdadeiro ser humano, com sentimentos reais, pode ser externamente bastante diferente das pessoas entre as quais elas vivem, mas interiormente é composto pelo mesmo material humano (RUSSELL, 1951, p. 205, grifos nossos).

Curar o provincialismo no espaço e tempo parece constituir, então, nossa proposta basilar para uma educação matemática dedicada a enfrentar a intolerância religiosa e promover, desta maneira, um ensino de matemática mobilizado contra o ódio. De fato, é perniciosa a constatação de que os educandos ouvem pouco sobre sociedades de culturas diversas no decorrer do processo educativo e de que os currículos permanecem mobilizados de modo a promover a pretensa neutralidade da matemática e, com isso, se omitem diante das agressões constantes, motivadas, sobretudo, pela intolerância religiosa (VALLE, 2014).

Bertrand Russell pode, evidentemente, colaborar na construção e no desenvolvimento de teorias que possibilitem repensar a educação matemática (VALLE, 2015), mas também é necessário e urgente refletir sobre a forma escolar e a prática docente situadas em meio ao cenário descrito. Espera-se, então, que este artigo possa oferecer elementos para o debate e para a reflexão sobre as dúvidas a que nos dedicamos, mas, mais que isso, espera-se que outros artigos, diálogos, práticas e posturas diante da educação matemática sejam instigados pelo caminho aqui percorrido.

\section{Notas}

1 É importante evidenciar que em nenhum momento na obra russelliana os termos relacionados ao místico (misticismos, religiões, crenças, fé...) são utilizados de modos pejorativos - verifica-se esta afirmação observando que, em todas as críticas aos "cristãos" e religiosos, Russell acrescenta adjetivos que demonstram sua compreensão de que a fé, em si, não constitui um mal.

2 O mesmo ocorre certamente com Pitágoras e provoca a "crise dos incomensuráveis", um momento de muita tensão na história da matemática. Sobre este momento, nos narra e comenta Russell: "Pitágoras sustentava que a essência constitutiva de todas as coisas era o número; e, no entanto, não existiam dois números que pudessem exprimir a razão entre o lado do quadrado e a diagonal. Parece provável que, sem nos apartarmos de seu pensamento, possamos explicar sua dificuldade supondo que ele encarava o comprimento de uma linha como determinado pelos átomos nela contidos - uma linha de duas polegadas conteria o dobro de átomos de uma linha de uma polegada, e assim por diante. Mas se esta era a verdade, não poderia deixar de haver razão numérica definida entre dois comprimentos quaisquer, pois presumia-se que o número de átomos em cada um deles, fosse qual fosse $o$ 
tamanho, era necessariamente finito" (RUSSELL, 1966, p. 124).

3 Sobre tais modos de conceituar, interpretar, a matemática, consideramos relevante o seguinte artigo em que o autor examina como operam tais conceituações em três momentos históricos distintos: From Ea, through Pythagoras, to Avatar: different setting for Mathematics, de Ubiratan D'Ambrosio, publicado nos Proceedings of the $34 \mathrm{~h}$ Conference of the International Group for the Psychology of Mathematics Education/ PME em Belo Horizonte, 2010.

4 Todas as demonstrações em matemática partem da assunção de determinados pressupostos - os axiomas - cuja veracidade não deve ser questionada. A assunção da validade destes axiomas faz com que todo o corpo de conhecimentos matemáticos se torne questionável sob uma perspectiva diferente da que fora assumida de início. As geometrias não-euclidianas demonstram, com o rigor próprio da matemática e de maneira muito inteligente, o que ocorre quando questionamos a validade de um axioma.

$5 \mathrm{O}$ mesmo vale, evidentemente, para a ciência e Russell destacou esta percepção no seguinte excerto, onde se nota, inclusive, a mesma postura conciliatória com que iniciamos este artigo: "os homens, às vezes, falam como se o progresso da ciência devesse necessariamente ser próspero para a humanidade, mas temo que seja uma das ilusões confortáveis do século dezenove que nossa iludida época deve descartar. A ciência permite que os detentores do poder realizem seus propósitos mais completamente do que poderiam sem ela. Se seus propósitos são bons, é um ganho; se são maus, é uma perda. $\mathrm{Na}$ era presente, parece-me que os propósitos dos detentores do poder são em maioria maus, no sentido de que envolvem uma diminuição, no mundo como um todo, das coisas que os homens pensam que são boas. Portanto, no presente, a ciência causa mau aumentando o poder dos poderosos. A ciência não é substituta da virtude; o coração é necessário para um boa vida assim como a mente" (RUSSELL, 2005, p. 57-58).

\section{Referências}

RUSSELL, B. New hopes for a changing world. Londres: Unwin Brothers, 1951.

Ensaios Impopulares. São

Paulo: Companhia Editora Nacional, 1956.

- Misticismo e Lógica. São

Paulo: Companhia Editora Nacional, 1957.

Retratos de Memória. São

Paulo: Companhia Editora Nacional, 1958.

. Nosso conhecimento do mundo

exterior. São Paulo: Companhia Editora Nacional, 1966.

. O casamento e a moral. São

Paulo: Companhia Editora Nacional, 1977.

. Religion and Science. New

York: Oxford University Press, 1997.

. Icarus or the future of Science.

Nottingham: Spokesman, 2005.

VALLE, J. C. A. do. História oral: uma possibilidade de justiça cognitiva no currículo. Revista Ars Histórica, 7, 124-138, 2014.

Insubordina-te, educação matemática! Responsabilidade e paz em Bertrand Russell. 2015. 266f. Dissertação (Mestrado). Faculdade de Educação, Universidade de São Paulo. São Paulo, 2015.

\section{Sobre o autor}

Júlio César Augusto do Valle: Licenciado em Matemática pela Universidade de São Paulo (USP), mestre e doutorando em Educação pela mesma universidade; pesquisador do Grupo de Estudos e Pesquisas em Etnomatemática (GEPEm) desde 2012. Tem se interessado por questões que buscam tematizar as dimensões políticas e filosóficas do ensino de Matemática. 
Recebido em junho de 2015.

Aprovado em fevereiro de 2016. 